\title{
MUJER Y CAMBIO SOCIAL EN EL MUNDO ARABE
}

\author{
Gema Martín Muñoz
}

Universidad Autónoma de Madrid

RESUMEN. Las sociedades árabes afrontan desde las últimas décadas un proceso acelerado de transformación socio-económica que está modificando las estructuras familiares tradicionales, mientras la ley continúa «sacralizando» el viejo orden patriarcal y las ideologías oficiales siguen extendiendo el ideal tradicional de sociedad. La disfunción social, las contradicciones jurídicas y los desafíos demográficos que engendra esta doble dinámica son el objeto de estudio de este artículo.

A pesar de la diversidad de poblaciones, tradiciones y regímenes políticos que engloban los veintidós países del conjunto árabo-islámico (Norte de Africa y Medio Oriente), estas naciones presentan con respecto a la cuestión de la mujer y la familia una considerable homogeneidad, resultado del recurso a una fuente común de inspiración: el Islam.

Así, pues, abordar dicho tema en el marco árabo-islámico exige analizar no sólo la dimensión sociológica, sino también su fundamento religioso, del que se derivan importantes factores nacionalistas y de identidad cultural.

Si a nivel sociológico la familia en los países árabes se define por su carácter patriarcal y patrilineal (lo que, no hay que olvidar, se corresponde con el fondo común de todas las civilizaciones mediterráneas), a nivel ideológico se caracteriza por su marcada dimensión religiosa, dado que los Códigos de la familia con que cuentan los Estados árabes se inspiran todos en la chari'a o ley islámica.

\section{Reis}


Mientras el derecho positivo ha alcanzado al código civil o penal en la mayor parte de esos países (excepción hecha de Arabia Saudí y algunos de sus vecinos del Golfo), el estatuto familiar y personal (matrimonio, relaciones conyugales, relaciones padres e hijos, herencia...) es regulado de acuerdo a principios islámicos que consagran un modelo familiar jerarquizado en el que, en mayor o menor medida, se consagra la autoridad del marido sobre la esposa, del padre sobre la hija, del hermano sobre la hermana ${ }^{1}$.

\section{LA DIMENSION JURIDICA}

Los códigos de la familia - cada país ha promulgado el suyo propionacieron con los Estados-nación a fin de establecer un conjunto legal unificado sometido al control del Estado, de manera que se corrigiesen las interpretaciones subjetivas o las costumbres locales arcaicas, fruto del sistema doctrinal y no legislativo precolonial. Pero en todos ellos de forma tan timorata que siguieron consagrando un modelo de familia árabo-musulmana de dominante patriarcal y agnática que conserva plenamente su actualidad y cuya modificación es interpretada culturalmente como un atentado a la identidad islámica. Y más aún cuando la educación de base recibida en la casa, la escuela o la mezquita valora esos fundamentos tradicionales en los que reposa la organización social y ética de la familia musulmana.

Así, mientras las mujeres alcanzaban los derechos políticos y accedían a la escolarización y al trabajo remunerado, los Códigos perpetuaban un modelo social arcaico y en contradicción con dicho progreso.

Un análisis comparado de los diferentes códigos permite establecer los puntos de encuentro que existen entre todas estas leyes y las cuestiones que las distancian, dado que la interpretación de los principios islámicos ha variado según el espíritu aperturista o conservador de los redactores de dichos códigos ${ }^{2}$.

' La chari'a o ley islámica se basa en las fuentes sagradas: el Corán y la Sunna (tradición), compuesta por los hadizes o «dichos» adjudicados al Profeta a lo largo de su vida. De la interpretación de estas fuentes sagradas, los jurisconsultos musulmanes elaborarán el fiqh o derecho islámico, de acuerdo con cuatro escuelas jurídicas ortodoxas: la malikí, la chafi'i, la hanbali y la hanafi. Desde finales del siglo xix, el derecho positivo entrará en la mayor parte de las legislaciones árabes por influencia europea (a veces por imposición colonial) para dominar, no sin conflicto, toda la escena legal, salvo en el caso de los códigos de la familia, el derecho de sucesión y los bienes waqfs (bienes de manos muertas que aseguran los ingresos de las fundaciones piadosas).

${ }^{2}$ El código tunecino, respondiendo a la voluntad modernizadora de Habib Burguiba, debe ser considerado, con diferencia, el texto más avanzado del mundo árabe. Asimismo, esa misma voluntad modernizadora en Iraq, Siria y Egipto se ha reflejado en leyes que, si bien no han llegado nunca al nivel de la tunecina, profundizaron más en su afán por corregir ciertas situaciones pésimas para la mujer. Por el contrario, si dejamos aparte la situación en la Península Arábiga, el argelino es uno de los más manifiestamente retardatarios. 
La primera característica que les une a todos ellos es el haber sido promulgados tras las independencias (Marruecos, 1957-58; Túnez, 1956 - completado por dos decretos en 1964-; Argelia, 1984; Iraq, 1959; Siria, 1953 -reformado en 1975-; Sudán, 1960 -reformado en 1967-; Egipto, 1920; Jordania, 1951 - reformado en 1976-; Yemen del Sur, 1974; Kuwait, 1984; Emiratos Arabes, 1979 — refrendado en 1982-) y no haber sido prácticamente modificados desde entonces a pesar de las evoluciones experimentadas por esas sociedades ${ }^{3}$.

Asimismo, todos ellos van dirigidos a los musulmanes, lo que establece una comprensión de la ciudadanía a través de comunidades confesionales, «sociedades de creyentes», que no ahondan en la constitución de «sociedades de individuos». La comunidad se impone sobre la sociedad ${ }^{4}$.

Todos penalizan la familia ilegítima fuera del matrimonio, protegen la ética sexual, consideran a la mujer una eterna menor y establecen un modelo familiar patrilineal: la filiación se establece siempre por vía paterna y en matrimonio legítimo (la filiación natural de padre no existe); la tutela (poder de «dirección», de educación de los hijos menores, de gestión de su patrimonio, su representación legal y el poder de consentir a su matrimonio) pertenece siempre al padre ${ }^{5}$, y la custodia pertenece a la madre sólo hasta que dejan de ser menores. $Y$ patriarcal: se consagra la tutela del hombre sobre la mujer, sin que existan relaciones de reciprocidad o complementariedad que establezcan la igualdad entre ellos.

Incluso, en su misión de corregir abusos, los códigos no han logrado realmente afianzar los cambios que pretendían introducir, tanto por la tímida dimensión correctiva de la ley como por las grandes distancias existentes entre la letra y la costumbre, imponiéndose la segunda sobre la primera. Veamos los ejemplos más relevantes.

Todas las reglamentaciones «modernas» sobre la familia traslucen la

3 En Egipto, el estatuto familiar ha sido objeto de diversas transformaciones desde los años veinte. Las enmiendas de la ley fueron progresivamente avanzando con respecto a la situación de la mujer hasta 1979 , para en 1985 dar marcha atrás con respecto a lo logrado anteriormente en materia de divorcio y tutela. Con respecto a Sudán, la aplicación por el presidente Numeiri de la chari'a o ley islámica en 1983 empeoró en mucho la situación de la mujer sudanesa, sobre todo a partir del golpe de Estado que llevó al poder al general Omar al-Bachir en 1989. El caso del Líbano es más complejo dado el gran número de comunidades existentes en ese país. El código de la familia de los drusos data de 1948 y 1959, pero para los sunníes sigue en vigor la legislación otomana de 1917, reformada ligeramente en 1947.

* Existen, junto a los códigos islámicos, estatutos personales para los no musulmanes, dado que en algunos países árabes hay importantes minorías no musulmanas, como es el caso de los coptos en Egipto (en torno al 7 por 100 de la población); los maronitas en Líbano (45 por 100); siriacos jacobitas, armenios ortodoxos, melkitas y griegos ortodoxos en Siria (en total, 10 por 100 de la población); siriacos, caldeos, nestorianos, jacobitas y armenios católicos en Iraq ( 3 por 100 de la población), y griegos ortodoxos y melkitas en Jordania (3 por 100 de la población). Datos extraídos del Atlas du Monde Arabe, R. Boustani y P. Fargues, Bordas, París, 1990.

'Se diferencian a la hora de reglamentar la tutela en caso de fallecimiento del padre. En Túnez, ésta pasa a la madre, mientras en general pasa a la familia paterna vía varonil. 
voluntad de elevar la edad del matrimonio para impedir los enlaces impúberes ${ }^{6}$. Las causas de esta medida no se refieren sólo a razones de dignidad hacia la mujer, o de estabilidad familiar, sino también están relacionadas con la preocupación por el crecimiento demográfico, ya que en sociedades donde la fecundidad no es a menudo controlada el retraso de la edad del matrimonio tiene un impacto directo sobre la natalidad, cuestión sobre la que volveremos más adelante.

Sin embargo, la propia ley establece en muchos casos dispensas que, por ejemplo, en Siria e Iraq permiten el matrimonio a los 13 años en determinadas circunstancias, o con una «autorización especial del juez, por motivos graves y en interés de los dos esposos», en Túnez. También es el juez en Argelia el que puede derogar la ley en este sentido «por una razón de interés o en caso de necesidad». De hecho, en muchos casos estas cláusulas sirven para legalizar embarazos de menores protegiendo al progenitor que, convirtiéndose en marido, se libra de la condena por llevar a cabo actos sexuales sin violencia con menores (por ejemplo, cinco años de prisión en Túnez). No es difícil imaginar la inestabilidad conyugal de estos «matrimonios forzados».

Asimismo, aunque el consentimiento matrimonial $(\hat{y} a b r)$ por parte del padre o tutor de la novia ha sido suprimido, esta innovación puede ser soslayada en Marruecos «si se teme una mala conducta por parte de la novia», o si el tutor de la novia decide que «no le es provechoso el matrimonio», en cuyo caso decidiría el juez, como ocurre en Argelia. En otros casos, si bien el tutor no tiene derecho a forzar a la mujer al matrimonio no deseado, se exige su aprobación si la novia se casa antes de haber alcanzado la edad civil, como ocurre en la legislación marroquí (18 años) y tunecina (21 años); o si es virgen, caso de Jordania; o, como en Siria, para toda mujer que haya alcanzado la edad del matrimonio.

Con respecto a la poligamia, salvo en Túnez, donde el legislador la ha prohibido, el resto de los códigos tienden a limitar ese derecho del marido a tener cuatro esposas, pero sin atreverse a anularlo. Así, el código iraquí prohíbe más de una esposa a menos que exista el permiso del juez (y en caso de que el polígamo sea suficientemente rico y le venga de ello una ventaja legítima); por su parte, la ley siria reconoce la capacidad del juez a no autorizar la poligamia; en Marruecos, «si se teme una injusticia hacia las esposas la poligamia es prohibida», pero como la ley no hace intervenir al juez no se sabe «quién» dirimirá que una injusticia es de temer. Sin embargo, la mujer puede pedir al marido en el momento del matrimonio que se incluya una cláusula en el contrato matrimonial por la que se compromete a no ser polígamo y concederle la separación en caso contrario. Otra cosa es que, en la práctica, las mujeres se atrevan a solicitar ese derecho que recorta el libre albedrío del hombre.

- Así, por ejemplo, en Marruecos la ley establece la edad mínima en 18 para el hombre y 15 para la mujer; en Túnez, 20 y 17; en Libia, 18 y 16; en Argelia, 21 y 18; en Siria, 18 y 17; Jordania, 16 y 15; Líbano, 18 y 17; en Iraq, 18 para ambos sexos. 
Con respecto a la disolución del matrimonio, el repudio (derecho unilateral del marido a rechazar a su esposa sin que medie justificación ni reparación) sigue siendo un hecho fácil para el hombre y estando en completa vigencia. Excepción hecha de Túnez, donde el repudio está prohibido y el derecho al divorcio ante los tribunales se ha establecido en igualdad de condiciones para los dos cónyuges, los códigos y estatutos personales musulmanes sólo han tratado de dificultar su recurso y abierto a la mujer la posibilidad, en muy precisas circunstancias, de solicitar el divorcio por mediación de juez. Esas circunstancias en Marruecos han quedado estipuladas en: incumplimiento de la obligación de manutención por parte del marido, ausencia prolongada del hogar, vicio redhibitorio o perjuicio, o si media compensación económica. En Argelia, por enfermedades sexuales del marido, su ausencia del lecho durante más de cuatro meses, faltas morales reprensibles, ausencia del marido por más de un año sin excusa y sin cumplir su deber de mantenimiento. En Siria e Iraq, además de por esas razones y malos tratos, por disensión o prejuicio, probando incompatibilidad. En Egipto, por comportamiento violento, ausencia del marido o falta en su deber de manutención.

La importancia del deber de manutención del marido a la mujer (nafaqa) proviene de la división sexual que prevalece en la organización de la familia. Mientras el marido es obligado a cumplir con la manutención de la esposa, ella debe corresponderle reconociendo su autoridad y obedeciéndole. En realidad, la nafaqa infantiliza a la mujer colocándola bajo la protección económica y la dependencia de su marido. Por un lado, marca la separación entre el espacio público y el doméstico, obstaculizando el libre acceso de la mujer al mundo del trabajo asalariado (sólo en la ley tunecina el derecho de la mujer a trabajar es reconocido implícitamente). Por otro, convierte a la esposa en una menor temerosa de la capacidad del esposo a recurrir sin trabas al divorcio o repudio que la ley le permite.

Finalmente, con respecto a los derechos de herencia, siempre los descendientes varones reciben una parte doble a la percibida por las mujeres, en respeto al precepto así estipulado por el Corán. Si bien en el contexto histórico en que nace el Islam la consideración coránica de que la mujer tiene derecho a heredar la mitad del hombre ha de ser calificada como un importante progreso - el de reconocer a la mujer una personalidad jurídica receptora de derechos de sucesión-, mantener inamovible dicho principio es, además de una anacronía, traicionar el espíritu progresista coránico.

En este sentido, el caso libio y saudí merecen dos breves comentarios por dispares entre sí. Como ha sido señalado por diversos especialistas, la filosofia coránica con respecto a la mujer puede ser considerada en algunos sentidos vanguardista y es claro que tiende a corregir los abusos a los que etan sometidas las mujeres en las sociedades preislámicas. La posterior interpretación de la jurisprudencia islámica — fiqh - se encargará de hacer evolucionar la ley privilegiando los ejemplos coránicos que establecen la 
desigualdad entre los sexos e ignorando aquellos otros que favorecen la situación e independencia de la mujer?

En el caso de Libia, desde la reorientación del régimen por el coronel Mu'ammar al-Gaddafi en 1977 a favor de la Yamabiriyya («masocracia»), inspirada en su Libro Verde, no se reconoce en este país más inspiración legal que la del Corán mismo, rechazando toda la jurisprudencia islámica posterior ${ }^{8}$. Y ha sido en pro del respeto del espíritu coránico que en este país se ha prohibido la lapidación contra la adúltera (en vigor en Arabia Saudí en pro de la ley islámica), se ha reconocido la libre voluntad del hombre y la mujer para decidir su matrimonio, se ha condenado la poligamia y se ha abolido la paridad de condición (social, económica) entre los cónyuges, que, sin embargo, existe en otras legislaciones como la jordana, la siria o la marroquí.

Sin embargo, en Arabia Saudí el modelo familiar establecido, de acuerdo con el Corán y el fiqh hanbalí (rigorista y puritano), es, además de muy conservador, claramente segregacionista: el marido es el único habilitado, por su naturaleza masculina, para ganarse la vida (rechazo implícito a una vida profesional remunerada de la esposa); el divorcio-repudio es un derecho unilateral del hombre; aunque la esposa tiene derecho a un trato justo por parte de su marido en caso de poligamia, no puede exigir la igualdad de sentimiento y satisfacción sexual; asimismo, debe residir siempre en el domicilio conyugal salvo permiso expreso del marido; éste puede infligir a su esposa correcciones, incluso físicas'. Tanto por el control social como por ciertos decretos aplicados con celo por la policía religiosa, la mujer saudí no puede personarse sola en ningún espacio público. En realidad, es en el firme rechazo a los espacios mixtos, «propicios para caer en el adulterio», donde las autoridades religiosas encuentran su mejor argumento para contener el acceso de la mujer al trabajo remunerado, aunque la ideología pública del poder tiende a favorecer gradualmente este hecho. Justificado en pro del principio islámico del «interés público» (al-maslaba al-'amma), esta progresiva reorientación del poder político saudí se va imponiendo por la necesidad de aumentar la población activa nacional, a fin de controlar la presencia laboral masiva de extranjeros en el país. De hecho, los estudios han sido abiertos a las jóvenes desde los años cincuen-

Muy clarificador en este sentido es el capitulo introductorio del libro de Caridad Rurz de Almonovar, El Movimiento feminista egipcio, Universidad de Granada, 1989. Véanse también el estudio de Isabel FiERro, «La Mujer y el trabajo en el Corán y el Hadiz», en M." Jesús Viguera (ed.), La Mujer en Al-Andalus. Reflcjos bistóricos de su actividad y categorías sociales, Madrid-Sevilla, 1989, pp. 53-60, y mi artículo «Mujeres Musulmanas: del Corán a los Códigos de la Familia», en Cuadernos de Africa y América Latina, 9, 1992, pp. 39-49.

* Son rechazados incluso los hadizes al ser considerados contradictorios y manipulables por los sucesores del Profeta, que forjaron algunos de ellos para alzarse con la legitimidad. Véase Sarwat Anis AL-Assiouti, «Coran contre Fiqh. A propos du mariage selon le Livre Vert de Mu'ammar al-Qaddhafi», en Annuaire de L'Afrique du Nord, CNRS, París, 1979.

"Véase Olivier Carké, L'Utopie islamique dans l'Orient arabe, París, 1991, pp. 87-118. 
ta, aunque dejando esta cuestión bajo el control del Ministerio de Asuntos Religiosos, que vela por una rígida separación de sexos.

\section{LOS IMPERATIVOS DEL CAMBIO SOCIOECONOMICO}

La familia en el mundo árabo-musulmán, el modelo que consagra y el origen jurídico de su legitimidad se encuentran confrontados en la actualidad a importantes dilemas relacionados, de un lado, con el conflicto que enfrenta al derecho positivo con el islámico y, de otro, con las contradicciones que engendra la cohabitación de la tradición con los cambios que ha impuesto la transformación socioeconómica experimentada en las últimas décadas.

La convivencia entre el derecho positivo e islámico no ha sido siempre fácil, pero desde los años setenta se ha convertido en uno de los debates claves en el mundo árabe, fruto de la reivindicación de la reislamización de la ley que hacen poderosos sectores conservadores islámicos e islamistas, y en cuya cuestión reposan sobre todo problemas de legitimidad ${ }^{10}$.

Este hecho tiene particular resonancia y reflejo en el caso de los códigos de la familia, ya que, por una parte, se trata de una legislación basada en la ley divina, la chari'a, y, por otra, estas leyes, como hemos visto, dejan al criterio del juez diversas y muy importantes cuestiones. Dicha situación ha traído consigo graves ambivalencias que perturban a las sociedades árabes actuales. Los jueces más conservadores eluden todo aquello que de innovador pueda existir en esos códigos, alegando que no está legitimado por las fuentes sagradas y esgrimiendo la objeción de conciencia. Frente a esto, los importantes cambios sociales experimentados (escolarización, trabajo de la mujer, emigración) han, por el contrario, impulsado a otros jueces a realizar una interpretación positiva de la ley divina para adaptarse a esas nuevas circunstancias que en la sociedad tradicional no tenían lugar ${ }^{11}$.

En realidad, son los efectos socioeconómicos los que mejor están contribuyendo a modificar la estructura familiar y la situación de la mujer musulmana, mientras la ley continúa impertérrita y las ideologías oficiales siguen extendiendo el ideal tradicional entre la sociedad, temerosas de que con los viejos modelos se hundan también los valores morales árabomusulmanes sobre los que han construido parte de su legitimidad.

Las sociedades árabes se encuentran desde las últimas décadas en un proceso de cambio socioeconómico acelerado que ha transformado el hábitat

${ }^{10}$ La reivindicación de la reislamización de la ley ha tenido en algunos casos sus frutos: la Constitución egipcia desde 1971 reconoce la chari'a como fuente de legislación, creando una gran confusión legal; en Libia, desde 1977 sólo el Corán es reconocido como fuente de legislación; en Sudán, la ley islámica fue impuesta en 1983, y en Mauritania, en 1980.

11 Véase Bernard Botrveau, «1979-1985 le droit de la famille en question», MagbrebMacbrek, 127 (1990), pp. 51-65. 
(éxodo rural y proceso de urbanización), el medio laboral (paso de las ocupaciones tradicionales a las actividades industriales o terciarias nuevas) y ha traído consigo importantes evoluciones: la extensión de la escolarización (cambio en la relación padres e hijos), el acceso de la mujer al mundo salarial (fenómeno principalmente urbano), la transformación de la organización familiar consecuencia de la emigración masculina, la mundialización de los medios de comunicación que transmiten otros modelos sociales...

Consecuencia de estos cambios ha sido el declive de la familia «ampliada», de la antigua «gran familia» reagrupada en torno a la «gran casa» y a un jefe único, el abuelo paterno, el padre o el hermano mayor, que tiende a ser sustituida por agrupaciones más reducidas, particularmente en los espacios urbanos, donde la pareja y sus hijos son la célula de referencia. Así, en Egipto, de acuerdo con el censo de 1976, las familias nucleares representaban ya el 77,5 por 100 ; en Siria, el 52 por 100 en 1970 , y en Jordania, entre el 60 y el 70 por 100 . En Kuwait y Bahrein, donde el impacto de la modernización -entendida a través del consumo, telecomunicaciones, nueva burocracia a la occidental - ha sido enorme, las familias nucleares representaban en 1971 el 88 y 55 por 100, respectivamente.

Sin embargo, hay que resaltar que esas familias nucleares no han dejado de ser numerosas, con seis miembros como media, ni han experimentado necesariamente un cambio de actitud ante el modelo tradicional (en Kuwait, el 48 por 100 de los matrimonios siguen siendo pactados entre primos), aunque van aumentando los casos en que esta transformación está modificando las relaciones entre los sexos, privilegiando los valores individuales o las «estructuras de cooperación» en la familia y, en consecuencia, poniendo en tela de juicio el modelo patriarcal antiguo.

De hecho, en la actualidad, las sociedades árabes se resienten de inestables dualidades fruto de la marcada diferencia entre unos países y otros (donde son notables las distancias con respecto al nivel de libertad entre los sexos, del acceso al trabajo de la mujer, de la extensión de la escolarización...); del gran desequilibrio en el reparto de la riqueza y la educación (generando un abismo entre unas clases sociales y otras en su acceso a la modernidad); de un desarrollo desigual que ha engendrado una verdadera desconexión entre el campo y la ciudad. En resumen, la existencia de «sociedades paralelas», cuyos puntos de convergencia se expresan muy a menudo en términos de crisis y esquizofrenia cultural.

\section{LA DIMENSION DEMOGRAFICA: UN DESAFIO A LA CRISIS}

En el mundo árabo-islámico, una población que en 1900 alcanzaba los 35 millones de habitantes, en el año 2000 habrá aumentado a 280 millones. Es decir, no es tanto que en la actualidad esta región del mundo esté superpoblada como las indudables posibilidades que tiene de ello según su 
elevada tasa de crecimiento anual, que en ningún caso es inferior al 2,5, tratándose en buena parte de países con un enorme déficit económico, con insuficientes prestaciones sociales y grandes dificultades para proveer de alojamiento, formación profesional y empleo a sus habitantes ${ }^{12}$.

Un crecimiento demográfico incontrolado puede ser, además, causa de una gran disfunción social. La disparidad entre los segmentos de la sociedad que son afectados por el crecimiento (son las clases más desfavorecidas las más indefensas ante el control de la natalidad) puede traer consigo una gran alteración de la composición social si la tasa de nacimientos es muy elevada y no existe la suficiente movilidad para que los hijos de las capas pobres y analfabetas asciendan socialmente. Si no se controla este fenómeno, la demografía agigantará la franja social de los desfavorecidos.

Sin duda, las causas del crecimiento demográfico están relacionadas con los avances de la medicina y la higiene, que han reducido a nivel planetario los índices de mortalidad, así como con los altos niveles de analfabetismo y subdesarrollo, que dificultan la implantación de la planificación familiar en aquellos países árabes en que se ha puesto en marcha ${ }^{13}$.

Pero, como ha señalado Philippe Fargues ${ }^{14}$, es indudable que el ascenso demográfico está también muy relacionado con la propensión de las poblaciones árabes a tener familias numerosas, y ello debido a una entrada precoz en vida marital y a una exposición constante a la procreación, situaciones derivadas de la fijación de ciertas estructuras familiares, particularmente todo lo que rodea a las normas del matrimonio ${ }^{15}$.

Por un lado, hay que señalar la influencia de valores culturales muy enraizados como son la tradicional supravaloración del matrimonio en las sociedades árabes (el celibato definitivo no supera el 2 por 100 tanto para hombres como para mujeres) y la general creencia de que una familia numerosa es una bendición. Por otro lado, instituciones del matrimonio como la poligamia y el repudio (o el privilegiado acceso al divorcio del

12 Egipto y Argelia alcanzan una tasa anual de crecimiento del 3 por 100 , y Jordania y los países del Golfo llegan ya al 4 por 100. Todo ello hace que el rejuvenecimiento de la población se refleje en la actualidad en cifras como: el 65 por 100 de la población de los países árabes tiene menos de 25 años; en Marruecos, el 50 por 100 es menor de 20 años; en Argelia, el 60 por 100 es menor de 20 años, y en Egipto, el 50 por 100 no supera los 15 años. Atlas du Monde Arabe, op. cit.

${ }_{13}$ De acuerdo con el censo argelino de 1987 , el analfabetismo alcanzaba al 31,3 por 100 de las mujeres argelinas; según el censo marroquí de 1982, al 56,2 por 100 de las marroquíes, y de acuerdo con el censo de Túnez de 1984, al 30,8 por 100 de las tunecinas. Según una encuesta realizada en Túnez y Jordania, cuando la esposa no ha frecuentado la escuela tiene una tasa de reproducción del 2,7 por 100 , en el caso tunecino, y del 3,7 por 100, en el jordano. Mientras que entre aquellas mujeres que han ido al colegio la tasa es de 1,5 y 2 por 100 , respectivamente.

if Philippe Fargues, «La démographie du mariage arabo-musulman: tradition et changement», Maghreb-Machrek, 116 (1987), pp. 59-73.

15 En Libia, los países de la Península Arábiga, Siria y Jordania, la media de hijos por mujer supera los 7; en Argelia, Sudán, Iraq y Mauritania, la media es entre 6 y 7; en Egipto y Marruecos, entre 5 y 6 , y en Túnez y Líbano, menos de 5 . Cifras todas ellas para el período 1985-1990. Atlas du Monde Arabe, op. cit. 
hombre) son instrumentos que permiten absorber el excedente de mujeres jóvenes en edad fértil, numéricamente mayores que los hombres. De ahí el elevado porcentaje de matrimonios con gran desigualdad de edad. Además de cubrirse el surplus de mujeres casaderas y en edad de procrear, se facilita que la larga fertilidad del hombre sea siempre correspondida por una mujer en período de procreación ${ }^{16}$.

La dote también favorece el mercado matrimonial y facilita legal y moralmente el repudio, ya que, aunque puede parecer una garantía económica para la mujer en caso de ser repudiada, es también una autorización legal para repudiarla y una descarga no menos legal de la obligación a mantenerla ${ }^{17}$.

La costumbre del matrimonio preferencial entre primos (casar a la hija con un hijo del tío paterno -endogamia-), práctica de raíz sobre todo rural y que, por ello, el éxodo a la ciudad ha debilitado al separar al clan, viene a asegurar también la universalidad del matrimonio, pactado y fijado, además de garantizar que la dote se queda en la familia y la herencia de la hija también.

Unido a todos estos elementos hay que destacar que el modelo musulmán de la familia consagra la consideración de la mujer como madre y educadora de los hijos. Hijos que, por otro lado, son la garantía para «consolidar su posición» en una institución matrimonial «inestable» como es la que se basa en la dependencia socioeconómica del hombre y la amenaza del repudio y la poligamia.

No sólo es gratuita la trivial consideración de que el acceso de la mujer al trabajo remunerado agrava la crisis porque agudiza el problema de la falta de empleo, sino que, por el contrario, su permanencia en el hogar eleva la tasa de fecundidad y crea un surplus de población que pone en peligro el equilibrio socioeconómico interno. Es opinión generalizada entre los demógrafos que «si los programas de control de natalidad seguidos en los países en desarrollo han contribuido ampliamente a dar un giro decisivo a comienzos de los años setenta en materia de fecundidad, ha sido por el esencial papel que en esta evolución ha desempeñado el avance de la emancipación femenina, consistente sobre todo en una mejora del nivel de educación de las mujeres, un retroceso en la edad del matrimonio y una mayor participación en la actividad económica» ${ }^{18}$.

16 Es necesario señalar que está mucho más extendida la vía del repudio o el divorcio antes de iniciar otro matrimonio que el recurso a la poligamia, infrecuente en la actualidad. Entre el 3 y 5 por 100 de los hombres casados en el mundo árabe son polígamos. En Túnez y Argelia suponen menos del 1 por 100; en Egipto eran el 1 por 100 en 1970; en Kuwait y Emiratos Arabes Unidos el índice es mayor: 12 y 6 por 100, respectivamente, en 1975. FARGUES, op. cit.

17 La dote (mabr) que ofrece siempre el novio consta de dos partes: el muqaddam, que se cumple antes del matrimonio, y el mu'ajar, que recibe la mujer en caso de repudio.

18 A. Chevallitr y V. Kesslek, «Economies en developpement et défis démographiques», en Notes et Etudes Documentaires, núm. 4878 (1989), La Documentation Française, París, p. 13. 
Si tomamos el ejemplo de aquellos países árabes en los que el Estado ha tomado una iniciativa firme de organizar campañas de planificación familiar para controlar la crisis socioeconómica que les atenaza, observaremos que las tasas más bajas de natalidad alcanzadas son inversamente proporcionales al nivel de conservadurismo del código de la familia, es decir, del vigor de las estructuras patriarcales. Así, vemos que, entre los países del Norte de Africa, Túnez va a la cabeza en el control de la natalidad, seguido de Egipto, Marruecos y Argelia ${ }^{19}$.

En conclusión, la evolución de la estructura tradicional familiar es un factor que está directamente vinculado al desarrollo y al control de la crisis socioeconómica en el mundo árabe de hoy, y más aún cuando soluciones coyunturales, como pudo ser en un tiempo la válvula de escape de la emigración, los tiempos actuales están demostrando más que nunca su carácter provisional (cierre de fronteras en Europa, recesión en los países del Golfo, «pre-industrialización» de Iraq tras la guerra del Golfo). Asimismo, son los imperativos del insoslayable cambio social los que están gradualmente imponiendo la transformación de caducas estructuras patriarcales, que en lo político e ideológico siguen siendo ampliamente defendidas y justificadas.

19 En Túnez, en 1961 se legalizó la venta de contraceptivos y su publicidad; en 1964 se lanzó el primer programa de planificación familiar con la meta -alcanzada- de llevar la tasa bruta de natalidad del 45 por 1.000 en 1962 al 35 por 1.000 en 1975 ; en 1965 se liberalizó el aborto. Egipto también inició su primer programa de planificación familiar en 1964, aunque en este país el aborto sólo es permitido si hay riesgo para la vida de la madre y el uso de la contracepción ha tenido que ser legitimado por un decreto religioso del gran mufti de Al-Azhar en 1988. En Marruecos se iniciaron los programas de planificación en 1967, y en Argelia esto no ha tenido lugar hasta 1983, y donde, si bien se ha experimentado un descenso de la natalidad desde 1986, la transición demográfica no se acaba de dibujar. Susan E. Marshall, «Politics and Status in North Africa», en Economic Development and Cultural Change, abril 1984. 